\title{
Microstructure and Mechanical Properties of Micro-Alloying Modified Al-Mg Alloys
}

\author{
J. Zhang \\ College of Materials Science and Engineering \\ Chongqing University \\ Chongqing, China
}

\author{
J.J. Zhao \\ College of Materials Science and Engineering \\ Chongqing University \\ Chongqing, China
}

\author{
R.L. Zuo \\ College of Materials Science and Engineering \\ Chongqing University \\ Chongqing, China
}

\begin{abstract}
Er and $\mathrm{Sr}$ were added to $5052 \mathrm{Al}$ alloy to investigate their possible effects on the microstructure and mechanical properties of the alloy. The results show that while $\mathrm{Sr}$ addition has a moderate grain refinement effect and has no positive effect on alloy plasticity, $\mathrm{Er}$ addition refines both the grain size and $\mathrm{Al6Fe}$ intermetallics and obviously improves the tensile elongation from $12 \%$ for 5052 alloy to $20 \%$ for Er-containing alloy. It is also revealed that $\mathrm{Er}$ either dissolves in the matrix or combines with $\mathrm{Fe}$ and $\mathrm{Si}$ and that $\mathrm{Er}$ can purify the alloy by eliminating impurity elements $\mathrm{Fe}$ and Si from the melt and Al-matrix.
\end{abstract}

Keywords-5052 Al alloy; micro-alloying; microstructure; mechanical properties

\section{INTRODUCTION}

With the increased demand of energy saving and pollution reduction, Al-Mg series (5XXX) alloys is increasingly used in automotive and transportation industry due to their high specific strength, wieldable, good workability and corrosion resistance [1]. Al-Mg alloys are non-heat treat hardening but derive their strength from solid solution strengthening and strain hardening. It has been shown that micro-alloying is an effective way to further strength the alloys. Alloying elements such as Sc, La, Ce, $\mathrm{Y}, \mathrm{Nd}, \mathrm{Zr}, \mathrm{Er}$, Sr have been added to high-Mg-containing Al-Mg alloys, especially 5083 aluminium alloy [2-9]. However, the role of alloying addition on low-Mg-containing Al-Mg alloys has not been studied. Comparatively, low-Mg-containing Al-Mg alloys have better formability and are more suitable for large wrought products. Demand in light rail train, coal conveyor, refrigerated truck, etc., requires larger width $\mathrm{Al}$ sheets, which in turn, raises higher formability requirement in order to ensure a homogenous deformation along width direction. In consideration that rare earth addition is beneficial to both microstructure and properties [10], micro-alloying elements $\mathrm{Er}$ and $\mathrm{Sr}$ have been added to $5052 \mathrm{Al}$ alloy, a typical low-Mg-containing alloy, and their modification role on the as-cast microstructure and mechanical properties are investigated.

\section{EXPERIMENTAL PROCEDURES}

Commercial $5052 \mathrm{Al}$ alloy was used as base alloy. Minor Er and $\mathrm{Sr}$ were added. The chemical composition was analyzed by inductively coupled plasma emission spectrometer (ICP) and is shown in Table 1 . The alloys were prepared by mold casting. Samples sectioned from the center of the ingots were polished and etched for microstructure observation, by optical microscope and TESCAN VEGA II scanning electron microscope (SEM) equipped with INCA Energy 350 energy dispersive X-ray spectrometer (EDX). The grain size was measured by the mean liner intercept method. The phase transformations during the solidification of these alloys were characterized by employing a NETZSCH STA449C simultaneous thermal analyzer. In the DSC testing, samples of $30 \mathrm{mg}$ were heated to $700{ }^{\circ} \mathrm{C}$ for $5 \mathrm{~min}$ and then cooled at a controlled speed of $15 \mathrm{~K} / \mathrm{min}$ under flowing argon. Microhardness was measured using a Vickers micro-hardness tester with a load of $50 \mathrm{~g}$ and duration of $10 \mathrm{~s}$. Cylindrical samples of $56 \mathrm{~mm}$ gauge length and $13 \mathrm{~mm}$ diameter were cut from the ingots for tensile mechanical testing.

TABLEI. CHEMICAL COMPOSITIONS OF THE EXPERIMENTAL MATERIALS(WT\%)

\begin{tabular}{lccccccccc}
\hline \multicolumn{1}{c}{ Alloy } & $\mathrm{Si}$ & $\mathrm{Fe}$ & $\mathrm{Cu}$ & $\mathrm{Mn}$ & $\mathrm{Mg}$ & $\mathrm{Cr}$ & $\mathrm{Ti}$ & $\mathrm{Er} / \mathrm{Sr}$ & $\mathrm{Al}$ \\
\hline 5052 & 0.070 & 0.417 & $<0.1$ & $<0.1$ & 2.25 & 0.14 & 0.006 & $/$ & Balanced \\
$5052+\mathrm{Er}$ & 0.081 & 0.665 & $<0.1$ & $<0.1$ & 2.27 & 0.10 & 0.020 & 0.30 & Balanced \\
$5052+\mathrm{Sr}$ & 0.070 & 0.460 & $<0.1$ & $<0.1$ & 2.41 & 0.14 & 0.006 & 0.028 & Balanced \\
\hline
\end{tabular}




\section{RESULTS AND DISCUSSION}

\section{A. Microstructure}

The as-cast microstructures of 5052 base alloy and $\mathrm{Er} / \mathrm{Sr}$ modified alloys were shown in Figure1. The microstructures manifest dendritic morphology with the second phase distributed along grain boundaries. The grain size of 5052 alloy is within 200 300 $\mu \mathrm{m}$. With $\mathrm{Er} / \mathrm{Sr}$ addition, the grain sizes are much reduced. As the same time, the amount of the secondary phases is obviously increased with Er addition while $\mathrm{Sr}$ addition does not influence the amount of the particles. The volume fraction of the particles was measured to be $2 \%, 3 \%$ and $2 \%$ for the base alloy, the alloy with Er and Sr additions, respectively.
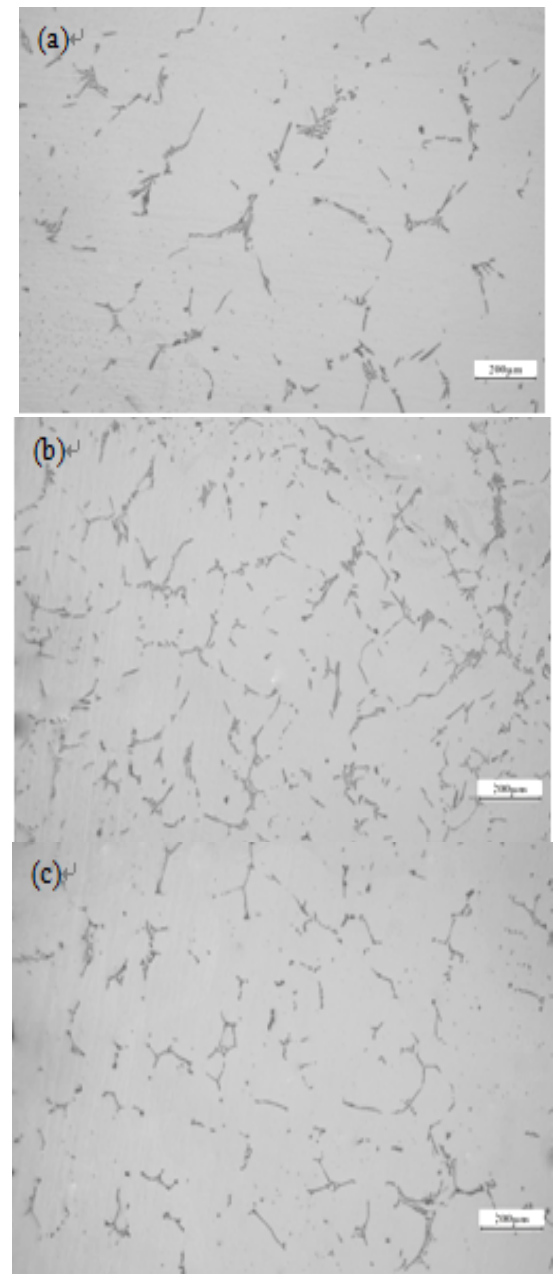

FIGUREI. AS-CAST MICROSTRUCTURES OF 5052 ALLOYS: (A) BASE ALLOY, (B) WITH ER ADDITION, (C) WITH SR ADDITION

\section{Thermal Analysis}

DSC curves of the as-cast alloys are shown in Figure 2. The addition of $\mathrm{Er}$ and $\mathrm{Sr}$ does not change the phase transformation characteristics. The exothermal peak on the cooling curves corresponds to the crystallization of the $\alpha-\mathrm{Al}$ matrix. However, it is noted that the addition of $\mathrm{Er}$ and $\mathrm{Sr}$ does change the characteristic temperatures. The initial temperature $\mathrm{TN}$, the peak temperature TM and the end temperature TR of the exothermal peaks are listed in Table 2. The solidification temperature range $\Delta \mathrm{T}(\Delta \mathrm{T}=\mathrm{TN}-\mathrm{TR})$ is also given in Table 2 . It can be seen that $\Delta \mathrm{T}$ decreases by micro-alloying and it decreases the most with Er addition. The smaller the solidification temperature range, the better the fluidity and filling performance of the alloy. Therefore, the addition of alloying elements, especially $\mathrm{Er}$, is beneficial to improve the casting performance of the alloy, which is important for large billet production. Furthermore, it is noted that the initial temperature increases incrementally with $\mathrm{Sr}$ and Er addition. This means that nucleation can occur at a relatively low undercooling temperature, a phenomenon which is normally associated with lower nucleation energy. From this point of view, the grain size of Er-containing alloy should be the finest, which accords with the microstructure observation results.

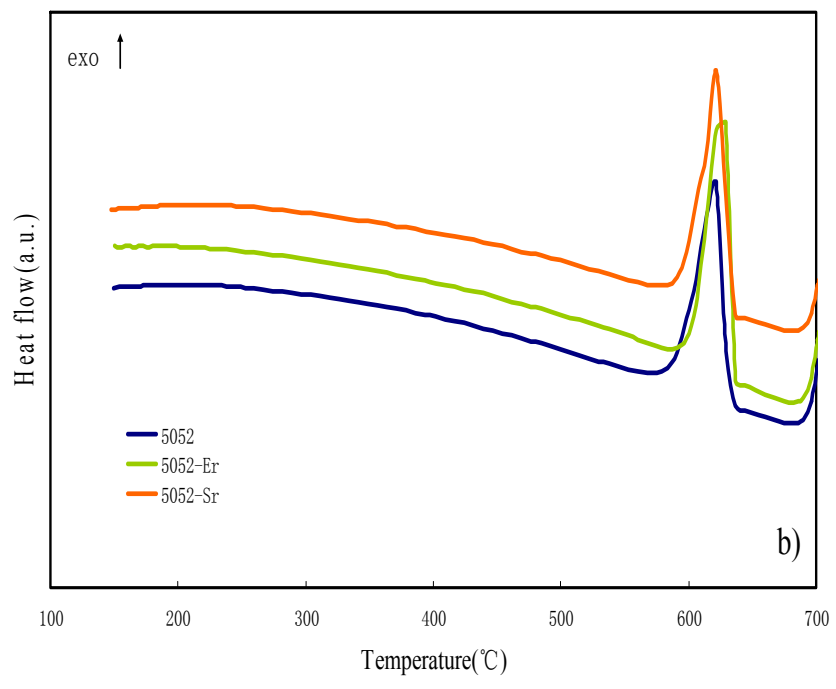

FIGUREII. DSC COOLING CURVES OF THE AS-CAST ALLOYS

TABLEII. THE CHARACTERISTIC TEMPERATURES (INITIAL TEMPERATURE TN, PEAK TEMPERATURE TM AND END TEMPERATURE TR) OF THE EXOTHERMAL PEAKS ON THE COOLING CURVES $\left({ }^{\circ} \mathrm{C}\right)$

\begin{tabular}{ccccc}
\hline Alloy & $\mathbf{T}_{\mathbf{N}}$ & $\mathbf{T}_{\mathbf{M}}$ & $\mathbf{T}_{\mathbf{R}}$ & $\Delta \mathbf{T}$ \\
\hline 5052 & 630.6 & 619.7 & 590.4 & 40.2 \\
$5052+\mathrm{Er}$ & 635.0 & 625.9 & 606.2 & 28.8 \\
& & & & \\
$5052+\mathrm{Sr}$ & 631.8 & 622.3 & 595.7 & 36.1 \\
& & & & \\
\hline
\end{tabular}

\section{B. Phase Constitution}

To determine the effect of micro-alloying addition on the phase constitution, SEM and EDS analysis were performed. In 5052 alloy, $\mathrm{Mg}$ is almost dissolved in $\alpha$-Al matrix. Impurity elements $\mathrm{Fe}$ and $\mathrm{Si}$ exist in the form of intermetallic Al6Fe and $\mathrm{Mg} 2 \mathrm{Si}$ phases. With $\mathrm{Sr}$ addition, the phase constitution does not show detectable change. After adding Er, no Mg2Si particles were detected, instead, Si combined with Er, as illustrated by arrow A in Figure 3 whose composition is also inserted in the figure. Al6Fe phase still exist, however, the size is much 
reduced, being $\sim 100 \mu \mathrm{m}$ in 5052 alloy and $\sim 20 \mu \mathrm{m}$ with $\mathrm{Er}$ addition, respectively. Moreover, it is interesting to note that there is always minor Er detected in the Al6Fe phase. The results suggest that Er can purify the alloy by eliminating impurity elements $\mathrm{Fe}$ and $\mathrm{Si}$ from the melt and Al-matrix, thus diminishing their harmful effects. Furthermore, Er segregates in the front of the advancing solid/liquid (S/L) interface during the solidification and inhibits the growth of the secondary phase [11], resulting in a size reduction of the Al6Fe phase.

EDS results also reveal that there is certain amount of Er dissolved in the $\alpha-\mathrm{Al}$ matrix. Besides, it is found [12] that $\mathrm{Al}$ and Er have a stronger tendency than $\mathrm{Mg}-\mathrm{Er}$ and $\mathrm{Mn}$-Er to combine together, therefore there might be some Al3Er particles which can act as effective nuclei for the Er-containing alloy.

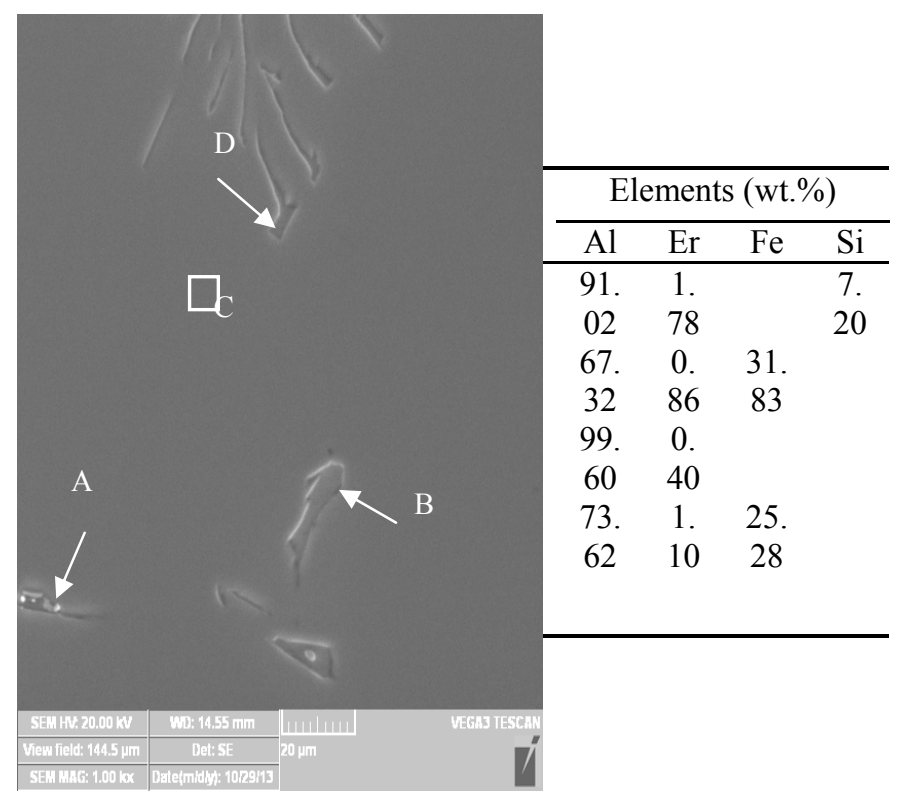

FIGUREIII. SEM MORPHOLOGY AND EDS ANALYSIS RESULTS OF THE ER-CONTAINING ALLOY

\section{Mechanical Testing}

Hardness testing shows that HV value remains almost unchanged with alloying element addition, being in the range of 47 50. Mechanical testing shows (Figure4) that tensile strength decreases a bit with alloying element addition, while the elongation is obviously improved with $\mathrm{Er}$ addition, increasing from $12 \%$ for 5052 alloy to $20 \%$ for Er-containing alloy. The improvement of elongation is beneficial to subsequent plastic deformation processing.

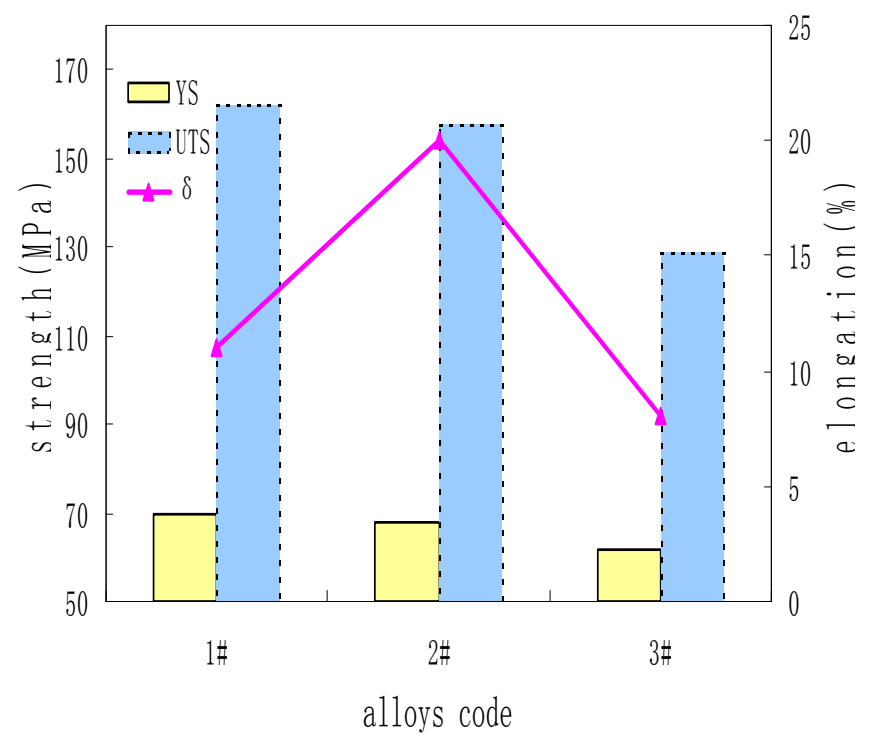

FIGUREIV. TENSILE MECHANICAL PROPERTIES OF THE ALLOYS. 1\#:5052 ALLOY \#2:5052+ER; 3\#:5052+SR

\section{CONCLUSIONS}

1) The as-cast microstructure of 5052 alloy has a typical dendritic morphology. The main phases are $\alpha-\mathrm{Al}$ matrix, intermetallic compounds $\mathrm{Al} 6 \mathrm{Fe}$ and $\mathrm{Mg} 2 \mathrm{Si}$.

2) Er addition refines both the grain size and the Al6Fe phase. Er either dissolves in the matrix or combines with $\mathrm{Fe}$ and $\mathrm{Si}$; $\mathrm{Er}$ can purify the alloy by eliminating impurity elements $\mathrm{Fe}$ and $\mathrm{Si}$ from the melt and Al-matrix.

3) Tensile elongation is obviously improved by Er, increasing from $12 \%$ for 5052 alloy to $20 \%$ for Er-containing alloy. The improvement of elongation is beneficial to subsequent plastic deformation processing.

4) Sr has a moderate grain refinement effect. Moreover, it does not change the phase constitution and has no positive effect on alloy plasticity.

\section{ACKNOWLEDGEMENTS}

The authors are grateful for the financial support of the International Technical Cooperation Project (2011DFR50950) by the Ministry of Science and Technology of China and sharing fund of Chongqing University's large scale equipment.

\section{REFERENCES}

[1] G.C. Blaze, Alcoa Green Letter: The 5000 Series Alloys Suitable for Welded Structural Applications, Aluminum Corporation of America, New Kensington, PA, 1972.

[2] K.E. Knipling, D.C. Dunand, D.N. Seidman, Criteria for developing castable, creep-resistant aluminium-based alloys-a review, Z Metallk 97 (2006) 246-265.

[3] Yang FB, Liu EK, Xu J, Shi LK. Effects of Er on the microstructures and mechanical properties of as-cast $\mathrm{Al}-\mathrm{Mg}-\mathrm{Mn}-\mathrm{Zn}-\mathrm{Sc}-\mathrm{Zr}-$ (Ti) filler metals. Acta Metall Sin 2008;44(8):911.

[4] J. Royset, N. Ryum, Scandium in Aluminum Alloys, Int. Mater. Rev. 50 (2005) 19-44.

[5] E. A. Marqis, D. N. Seidman, M. Asta, C. Woodward, Composition Evolution of Nanoscale Al3Sc Precipitates in an Al-Mg-Mn-Sc Alloy: Experiments and Computations, Acta Mater. 54 (2006) 119-130. 
[6] H.Z. Li, H.J. Wang, X.P. Liang, Y. Wang, H.T. Liu, Effect of Sc and Nd on the Microstructure and Mechanical Properties of Al-Mg-Mn Alloy, J Mater. Eng. Perform. 21 (2012) 83-88.

[7] A. K. Lohar, B. Mondal, D. Rafaja, V. Klemm, S. C. Panigrahi, Microstructural investigations on as-cast and annealed $\mathrm{Al}-\mathrm{Sc}$ and Al-Sc-Zr alloys, Mater. Charact. 60 (2009) 1387-1394.

[8] Z.X. Liu, Z.J. Li, M.X. Wang, Y.G. Weng, Effect of complex alloying of $\mathrm{Sc}, \mathrm{Zr}$ and $\mathrm{Ti}$ on the microstructure and mechanical properties of Al-5Mg alloys, Mater. Sci. Eng. A 483-484 (2008) 120-122.

[9] Q. Chen, Q.L Pan, Y. Wang, Z.Y. Zhang, J. Zhou, C. Liu, Microstructure and mechanical properties of Al-5.8Mg-Mn-Sc-Zr alloy after annealing treatment, J. Cent. South Univ. 19 (2012) 1785-1790.

[10] Z. R. Nie, T. N. Jin, J. X. Zou, J. B. Fu, J. J. Yang, T. Y. Zuo, Development on Research of Advanced Rare-earth Aluminum Alloy, Trans. Nonferrous Met. Soc. China, 13 (2003) 509-514.

[11] M.A. Easton, D.H. StJohn, A model of grain refinement incorporating alloy constitution and potency of heterogeneous nucleant particles, Acta Mater. 49 (2001) 1867-1878.

[12] J Zhang, C. Fang, F. Yuan, Grain refinement of as cast Mg-Mn alloy by simultaneous addition of trace Er and Al, Int. J. Cast Metal. Res. 25 (2012) $335-340$. 